\title{
A experiência de famílias não doadoras frente à morte encefálica
}

\author{
Non-donor families' experiences in cases of brain death \\ La experiencia de familias no donantes ante la muerte encefálica
}

\author{
Gabriela Camponogara Rossato' @ Nara Marilene Oliveira Girardon-Perlinil @

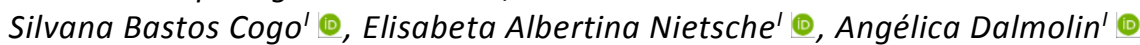

'Universidade Federal de Santa Maria, Santa Maria, RS, Brasil

\begin{abstract}
RESUMO
Objetivo: compreender a experiência vivenciada de famílias de adultos frente à morte encefálica e a opção pela não doação de órgãos. Método: estudo qualitativo fundamentado no Interacionismo Simbólico, realizado em um hospital público, no estado do Rio Grande do Sul, com seis famílias, que tiverem um familiar potencial doador de órgãos diagnosticado com morte encefálica e negaram a doação. Os dados foram obtidos por meio de entrevista narrativa no período de maio a novembro de 2016, após aprovação do Comitê de Ética da instituição, e analisados com ênfase no conteúdo. Resultados: refere-se a uma situação inesperada e desconhecida, de incertezas, dor e sofrimento ante o adoecimento, a morte encefálica e a decisão pela doação de órgãos ou não. Conclusão: Em um contexto interacional de incertezas, definido como o desmoronar da vida familiar por um evento inimaginável, a morte encefálica e a doação de órgãos é percebida como a intensificação da perda, o que corrobora na decisão pela não doação.
\end{abstract}

Descritores: Doença Aguda; Morte Encefálica; Obtenção de Tecidos e Órgãos; Família; Enfermagem.

\begin{abstract}
Objective: to understand the lived experience of adult families in cases of brain death and the option not to donate organs. Method: this qualitative study based on Symbolic Interactionism was conducted at a public hospital in Rio Grande do Sul state, with six families who had a potential organ donor family member diagnosed with brain death and who refused to donate. Data were obtained through narrative interviews between May and November 2016, after ethics committee approval, and analyzed with emphasis on content. Results: this was an unexpected and unknown situation of uncertainties, pain, and suffering from illness, brain death, and the decision whether to donate organs or not. Conclusion: in an interactional context of uncertainties, specifically the collapse of family life following an unimaginable event, brain death and organ donation were perceived to intensify the loss, which corroborated the decision to not donate.
\end{abstract}

Descriptors: Acute Disease; Brain Death; Tissue and Organ Procurement; Family; Nursing.

\section{RESUMEN}

Objetivo: comprender la experiencia vivida de las familias adultas en casos de muerte cerebral y la opción de no donar órganos. Método: este estudio cualitativo basado en Interaccionismo Simbólico se realizó en un hospital público del estado de Rio Grande do Sul, con seis familias que tenían un familiar donante potencial de órganos diagnosticado con muerte cerebral y que se negaron a donar. Los datos se obtuvieron a través de entrevistas narrativas entre mayo y noviembre de 2016, luego de la aprobación del comité de ética, y se analizaron con énfasis en el contenido. Resultados: se trata de una situación inesperada y desconocida de incertidumbre, dolor y sufrimiento por enfermedad, muerte cerebral y la decisión de donar órganos o no. Conclusión: en un contexto interaccional de incertidumbres, específicamente el colapso de la vida familiar tras un evento inimaginable, se percibió que la muerte encefálica y la donación de órganos intensificaban la pérdida, lo que corroboró la decisión de no donar.

Descriptores: Enfermedad Aguda; Muerte Encefálica; Obtención de Tejidos y Órganos; Familia; Enfermería.

\section{INTRODUÇÃO}

O transplante de órgãos pode ser a última alternativa de continuidade de vida. Entretanto, para as famílias dos potenciais doadores, este é um processo que as coloca frente à finitude da vida, a qual se revela no conceito de morte encefálica $(\mathrm{ME})^{1}$. O diagnóstico da $\mathrm{ME}$, definido como a perda completa e irreversível de todas as funções encefálicas, é condição para a doação de órgãos, pois, sua ocorrência caracteriza a morte da pessoa².

Ante à comprovação da ME, as Comissões Intra-hospitalares de Doação de Órgãos e Tecidos para Transplante (CIHDOT) são responsáveis pela educação e conscientização das famílias sobre a possibilidade de doação de órgãos e tecidos ${ }^{3}$. Compete a essa comissão conduzir a entrevista que consiste em uma reunião com a família na qual será socializado como ocorre o processo de doação de órgãos e tecidos, oferecendo informações para que possam tomar uma decisão ${ }^{1}$.

A reação familiar frente à comunicação de ME e a possível doação de órgãos tem sido objeto de diversos estudos. Uma revisão integrativa da literatura ${ }^{4}$ reporta que, ao receberem o diagnóstico de $\mathrm{ME}$, os familiares apresentam

Agradecimentos à Coordenação de Aperfeiçoamento de Pessoal de Nível Superior - Brasil (CAPES) - Código de financiamento 001.

Autora correspondente: Nara Marilene Oliveira Girardon-Perlini. E-mail: nara.girardon@gmail.com

Editora responsável: Sonia Acioli 
manifestações de tristeza, choro e revolta, e o desconhecimento relativo ao assunto os conduz a questionamentos e uma possível recusa na doação. Identificou, ainda, uma lacuna no que tange a assistência de enfermagem voltada às famílias que estão vivendo a situação de ME de um familiar ${ }^{4}$.

Para se posicionar em relação à doação, a família necessita compreender o que de fato é a ME. Contudo, este momento caracteriza-se como o mais delicado do processo, pois a responsabilidade para tal decisão é vivida em circunstâncias que envolvem dor, angústia, perda e interrupção de uma vida ${ }^{1,3}$. Pode-se inferir que a interpretação das interações presentes na experiência é percebida mais pela dimensão emocional do que a racional, e esta influenciará na decisão de doar ou não os órgãos.

No que tange a doação de órgãos, os dados da Associação Brasileira de Transplante de Órgãos, de janeiro a março de 2020, indicam que dos 2730 potenciais doadores notificados, 1.612 famílias foram questionadas sobre a intenção de doar ou não os órgãos, 577 negaram a doação e 965 doadores efetivos, o que corresponde à diminuição da taxa de não autorização familiar (36\%), pela primeira vez abaixo de $40 \%$, no Brasil ${ }^{5}$.

Embora haja avanços, estudos abordam os motivos relacionados a não doação de órgãos e a recusa familiar 6-12. As justificativas incluem a convicção prévia da não doação, desconhecimento da vontade do potencial doador, preservar a integridade do corpo pós morte e desacordo familiar ${ }^{6-7,9-10}$. Além disso, o receio com o tempo para liberação do corpo, o fato de não aceitar a ME como o fim da vida, as crenças religiosas e as situações em que a família não informa o motivo da não adoção ${ }^{8,11}$. Estes motivos ainda podem ser corroborados pelas subjetividades presentes na interação com a equipe que realiza as entrevistas para a captação ${ }^{12}$.

Neste contexto, percebe-se a necessidade de ampliar a compreensão relacionada à experiência das famílias que conviveram com o diagnóstico de ME de um familiar e optaram pela não doação de órgãos. Estudos dessa natureza contribuem para que enfermeiros e equipes de captação, ao interagir com as famílias, possam atentar para os sentimentos e significados presentes no contexto familiar, como dimensões que precisam ser avaliadas para direcionar e fundamentar a atuação profissional.

O estudo tem como questão de pesquisa: qual a experiência vivida de famílias de adultos frente à morte encefálica e a opção pela não doação de órgãos? O objetivo desses estudo foi compreender a experiência vivenciada de famílias de adultos frente à morte encefálica e a opção pela não doação de órgãos.

\section{REFERENCIAL TEÓRICO}

O Interacionismo Simbólico (IS) é um referencial teórico que busca compreender o comportamento e a ação humana, com base no significado, que o ser humano atribui às suas experiências, construído a partir das interações vividas que os indivíduos definem situações, elementos e comportamentos, interpretam-nos e agem ${ }^{13}$.

Este referencial possui três premissas que são: os seres humanos agem em relação aos fatos de acordo com os significados que têm para eles; o significado dos fatos surge da interação social que estabelecem com os outros; e, os significados são manipulados e modificados em decorrência de processos interpretativos efetivados pela pessoa quando esta lida com os fatos ${ }^{13}$. Assim, entende-se que a ação humana é resultado da interpretação daquilo que os indivíduos percebem no contexto em que estão inseridos, em relação aos outros e a si, sendo determinante para o seu comportamento. Os conceitos que integram o IS são: símbolo, self, mente, assumir o papel do outro, ação humana, interação social e sociedade ${ }^{13}$.

O estudo adotou o IS como referencial teórico por entender que a experiência da família ante a ME de um familiar e a doação de órgão é vivida em um contexto de interações sociais cuja ação da família é resultado do significado simbólico atribuído ao vivido ${ }^{13}$.

\section{MÉTODO}

Estudo qualitativo, fundamentado no $\mathrm{IS}^{13}$, realizado com famílias que tiverem um familiar adulto, com diagnóstico de ME e potencial doador de órgãos, internado na Unidade de Terapia Intensiva (UTI), de um hospital público do Rio Grande do Sul, e que se opuseram a doar. Para inclusão considerou-se os casos de ME identificados por busca ativa na UTI em 2016 e os casos registrados nos documentos da CIHDOT, anteriores a 2016. Foram excluídas as famílias que aceitaram a doação de órgãos e aquelas que desconheciam a condição clínica da ME do seu familiar, conforme informado pelos profissionais envolvidas na assistência.

Das 17 famílias que atenderam aos critérios de inclusão, sete foram excluídas pela impossibilidade de acesso devido a inexistência de registros de endereço ou telefone nos prontuários. Das dez famílias contatadas por telefone, seis aceitaram participar do estudo e quatro recusaram. A acessibilidade definiu o número de participantes. 
A coleta de dados foi realizada de maio a novembro de 2016, nas residências ou local de trabalho, conforme preferência dos participantes. Para a obtenção das informações utilizou-se a entrevista aberta, que durou em média 35 minutos, realizada sempre pela mesma pesquisadora, na forma de narrativa individual, audiogravada e norteadas pela questão inicial "Conte-me como foi a experiência de sua família em relação à situação de morte encefálica vivida com o seu familiar? Fale sobre a decisão da não doação de órgãos".

Os áudios foram transcritos e, posteriormente, deletados. O material produzido foi submetido à análise narrativa com organização de categorias com ênfase no conteúdo, incluindo as seguintes etapas: seleção do subtexto, definição das categorias de conteúdo, classificação do material em categorias e elaboração de conclusões a partir dos resultados ${ }^{14}$. A interpretação dos resultados deu-se à luz do IS.

O estudo foi aprovado por Comitê de Ética em Pesquisa, sob o parecer número 1.513.581. Para assegurar o anonimato dos participantes, as narrativas foram codificadas com a letra $F$ (famílias) seguida dos números de 1 a 6 , e, para os entrevistados, a letra $\mathrm{E}$, seguida dos números de 1 a 3 , para as famílias com mais de um participante.

\section{RESULTADOS E DISCUSSÃO}

Compuseram o corpus de análise os dados obtidos com seis famílias. Destas, três haviam vivenciado o processo de ME com recusa à doação de órgãos há mais de um ano, e três, a menos de um ano. Em quatro famílias participaram das entrevistas dois familiares, em uma participou três e, na outra, um familiar, totalizando 11 pessoas entrevistadas individualmente.

Nas seis famílias predominou o sexo feminino (sete). Com relação ao paciente em ME, quatro eram homens e duas mulheres, com idade entre 18 a 43 anos. O vínculo familiar foi: dois esposos(as), duas mães, uma filha, dois irmãos e quatro cunhados (as), com idades que variaram de 19 a 61 anos. Quanto a causa da ME quatro foram traumatismo crânio-encefálico e dois acidentes vascular cerebral hemorrágico. O tempo de internação na UTI foi de uma média de sete dias. No processo de análise organizou-se duas categorias, apresentadas a seguir.

\section{Uma situação inesperada e desconhecida: incertezas ante o adoecimento e a morte encefálica}

O contexto interacional e os acontecimentos com os quais as famílias precisaram interagir diante do adoecimento agudo, explicitam uma realidade inesperada, desconhecida e permeada por incertezas, que deixa seus membros desorientados e inseguros. Sem conseguir entender o que está acontecendo, sentem-se sem o controle da situação e oscilam entre sentimentos de angústia, tristeza e esperanças.

Uma coisa que nunca na minha vida imaginei. Nunca pensei que nós fossemos passar por isso. Fiquei paralisada, chocada. Nunca vi coisa igual, não tem como explicar em palavras. A gente tinha uma esperança que.... (F5-E1)

Eu sempre acreditando que ele ia melhorar, que iam fazer cirurgia, mas nada. (F3-E1)

A perplexidade indica que, inicialmente, a família não atribui significado ao fato vivido e, por isso, não consegue compreender o que está acontecendo e, tampouco agir diante de um objeto desconhecido, pois a interação social tornase simbólica quando possui significado tanto para o emissor quanto para o receptor da ação ${ }^{13}$. A família sente-se paralisada, necessitando de tempo para elaborar os significados relacionados aos novos fatos experienciados.

Complementa-se que ao saberem da hospitalização do familiar, a família não avalia a situação como preocupante, uma vez que eventos pregressos são considerados nessa avaliação. No entanto, ao chegar ao hospital defronta-se com a gravidade do quadro clínico e reage emocionalmente à notícia da ME, expressando-se por meio de choro, desespero e revolta.

A gente imaginou que ele tinha caído da moto e machucado um braço. Quando cheguei, olhei na porta de vidro da emergência, o meu irmão estava lá, aflito. Não tínhamos noção da gravidade. Depois o médico falou que era gravissimo e que a tendência era evoluir para morte cerebral. (F2-E1)

O meu filho ligou falando que o mais novo tinha sido baleado. Eu entrei em desespero. Eu chorei, fiquei muito revoltada. Não foi fácil receber uma notícia dessas e saber que ele dificilmente viveria. (F3-E1)

Na visualização do cenário da emergência e das condições físicas do familiar, na interação com os profissionais, com outras pessoas e consigo mesmo, cada membro da família vai processando as informações, compartilhando impressões e percepções e identificando os símbolos presentes nos fatos vividos. Símbolos são objetos sociais utilizados pelo ser humano para representação e comunicação, por meio dos significados que o indivíduo credita e que faz sentido a eles ${ }^{13}$.

A interação social torna-se simbólica quando possui significado tanto para o emissor quanto para o receptor da ação. É nesse processo de interação simbólica que a família vai compreendendo o fato vivido e definindo a ME. Um estudo destaca que, para as famílias, a situação de adoecimento agudo e inesperado, contribui para que a aceitação da condição de ME seja difícil, tornando a decisão sobre a doação, ainda mais complexa ${ }^{8}$. 
Outro estudo relacionado à decisão familiar sobre a doação de órgãos evidencia que a experiência das famílias se inicia no momento em que começam a viver o impacto da tragédia ${ }^{15}$, a qual é definida como um pesadelo, acompanhado de incertezas e preocupação com o prognóstico e o futuro. Frente a perplexidade do adoecimento agudo, do desespero que advém da má notícia, da internação do familiar e do risco de morte, as famílias vivenciam um processo de desorganização que dificulta assimilar o que está acontecendo ${ }^{15}$ e inicialmente, as famílias não consideram a morte como uma possibilidade ${ }^{16}$, o que indica essa interpretação como determinante para as ações adotadas pelas famílias.

Em um processo interno de interação consigo $(\mathrm{self})^{13}$, os membros da família individualmente e a família como unidade interativa acessam recursos que as auxilie no entendimento dos fatos. Assim, buscam elementos presentes em experiências de adoecimento prévio como modo de estabelecer conexão e prever a possível evolução do familiar. $A$ comparação resulta, sobretudo, da referência às doenças crônicas, em que a família pode acompanhar a trajetória, mas que confere uma expectativa diferente da evolução do quadro clínico agudo e, possivelmente, da morte como um desfecho inesperado.

Se fosse uma coisa que ela já tivesse, um câncer, ou outra doença, a gente tinha se preparado, mas foi de uma hora para outra, ficou pouco tempo no hospital. A gente esperava que ela respondesse, que ficasse mais tempo internada, mas não aconteceu. (F4-E1)

Foi tudo muito rápido, aconteceu em tão pouco tempo. A nossa vida acabou, abalou muito, abalou a todos. A vida da gente desmoronou. (F3-E2)

Ante o curto período de tempo decorrido entre o acidente, a internação e o diagnóstico de ME, as famílias referem dificuldade para assimilar o que estava ocorrendo e se reorganizar. Pode-se deduzir que o processo interacional estabelecido nesse contexto apresentou elementos simbólicos que a família não conseguiu significá-los no tempo da experiência, evidenciando dificuldade para agir deliberadamente ${ }^{13}$.

Diante de um evento inesperado que ameaça a vida e do sentimento de incerteza, em que a perda pode ser concretizada na notícia da ME, sobressai a dor e a impotência presentes no contexto familiar, que impede de dar sentido ao que estão vivendo.

\section{Da incerteza a decisão pela não doação de órgãos}

As famílias ao serem informadas da ME defrontam-se com outro fato, também inesperado e desconhecido: decidir sobre a possibilidade de doação dos órgãos. Permeadas por incertezas, medo e desconfiança, decidem pela não doação. Nesse processo consideram que a informação do diagnóstico de ME parece contrariar as evidências que indicam a presença de batimentos cardíacos e respiração, mesmo que controlada por aparelhos. Na interpretação da interação estabelecida referiram sentir-se "pressionadas" pela equipe de saúde e desconfiados da veracidade do diagnóstico de ME. Por considerarem a possibilidade de o familiar ainda estar vivo, não autorizaram a retirada dos órgãos, pensando que este poderia ter chance de sobreviver.

A gente fica se perguntando se não tinha nada mesmo para fazer. Quando falam de doação de órgãos, será que não apressam? Não ficam pressionando, apressando para dizer que a pessoa está morta mesmo, só para tirar os órgãos? (F2-E1)

Estudos apontam que a família se sente pressionada para tomar uma decisão rápida, sendo o intervalo de tempo entre a comunicação da ME e a informação sobre doação de órgãos importante para que ela possa organizar seus pensamentos e definir a decisão ${ }^{15-16}$. No entanto, este tempo não é respeitado pelos profissionais ${ }^{16}$. A ação humana, como resultado da interpretação das interações vividas, demanda tempo para reflexão sobre elementos simbólicos presentes no contexto, especialmente as informações recebidas, as circunstâncias da perda, a morte e a doação de órgão, pois a ação/decisão dependerá do significado atribuído por estes ${ }^{13}$

Como justificativa para a decisão pela não doação dos órgãos, as famílias mencionam a falta de comunicação e desconhecimento da opinião do familiar sobre o assunto, a revolta frente à situação e a morte inesperada do familiar e a existência de posições prévias para não querer doar.

\section{Ele nunca conversou sobre isso. A gente tem certeza disso! (F2-E3)}

Já tinham feito todo o processo de doação e, na última hora, eu disse não, não vou mais doar os órgãos! Porque Deus tirou ele de mim? Não vou doar mais. Me revoltei naquela hora. (F3-E1)

Eu pensei logo em não doar mesmo, porque ele não pediu em vida, se ele pedisse em vida eu doava. (F6-E2)

Os resultados corroboram com investigação que apresenta evidências do quanto é difícil para as famílias entender o que representa o protocolo de ME e aceitar que esta expressa a morte ${ }^{16}$. Embora o processo interacional estabelecido no ambiente hospitalar contribua para que as famílias entendam o que está acontecendo e, diante dos fatos, percebam a piora ou a não melhora do familiar, obstáculos na comunicação, assim como a dor e o sofrimento, podem dificultar a 
assimilação da realidade, levando membros da família a desenvolver alterações físicas e emocionais ${ }^{16}$, que podem dificultar o processo decisório.

Pode-se identificar que crenças de que o corpo ficaria mutilado e irreconhecível, caso concordassem com a doação, contribuíram para a decisão.

Meu coração quase saiu pela boca! Fiquei pensando: meu Deus do céu, ele todo rasgado, espicaçado, tirado os pedaços, tirado as coisas de dentro dele (referindo-se aos órgãos). Não seria mais ele! (F5-E1)

A tomada de decisão constitui-se em um momento difícil para a família, mas, sobretudo, para quem precisa ser o porta-voz da decisão, o que, por vezes, recaí sobre o membro da família presente no hospital e que, na operacionalização de um processo quase solitário, busca reunir informações que ajudem a pensar no que os demais membros da família, bem como o potencial doador, fariam em tal situação.

Foi horrível! Eu fiquei lá, sozinha, para tomar essa decisão. Como eu sabia que o pai dele não ia doar, então eu resolvi e disse que não.( F1-E1)

A dificuldade emocional presente nesse momento faz com que os familiares se sintam incompetentes para firmar uma posição definitiva ${ }^{15-17}$. Em contraponto, estudo evidencia que a decisão se torna amena para a família quando esta discutiu a respeito da doação de órgãos com o familiar que teve a $\mathrm{ME}^{18}$. Soma-se ainda, o fato que no contexto da entrevista realizada pelos profissionais de saúde para solicitar à doação pode constituir um obstáculo, pois a inabilidade na comunicação, tanto de médicos e enfermeiros, pode influenciar negativamente as famílias ${ }^{19}$. 0 papel de mediador, exercido pelo entrevistador, pautado em uma interação ética e segura, voltada ao cuidado e à atenção das necessidades das famílias, contribui à tomada de decisão ${ }^{19-20}$.

Algumas das famílias entrevistadas vivenciaram o diagnóstico de ME e a decisão de não doação há um ano ou mais, e percebeu-se que o tempo decorrido favorece reflexões sobre o vivido, promovendo ressignificações e o entendimento que, atualmente, poderiam agir de modo diferente.

Se fosse hoje eu aceitaria, mas como foi naquele momento. O que aconteceu foi um baque, que me revoltou muito, na hora aceitei e depois voltei atrás. Se fosse hoje, eu faria diferente. (F3-E1)

As informações fornecidas pela equipe de saúde sobre a ME nem sempre são objetivas e capazes de elucidar as dúvidas das famílias durante a conversa ${ }^{10}$. O diagnóstico de ME está definido na legislação brasileira ${ }^{2}$, mas o conceito, assim em outros contextos mundiais, parece ser desconhecido pela maioria da população, o que contribui para incertezas quanto a comprovação da morte da pessoa ${ }^{21}$. Entender que um familiar que apresenta batimentos cardíacos, movimentos respiratórios e temperatura corporal preservada está morto é difícil para a família, e explicar constitui tarefa árdua para os profissionais ${ }^{3}$. Muitas famílias ainda estão em estado de choque pela notícia da ME, quando são surpreendidas pela informação da possibilidade de doação dos órgãos ${ }^{16-17}$.

Ao relembrar o transcurso dos fatos relacionados ao vivido e ao familiar que morreu e refletindo sobre o modo como decidiram pela não doação, uma das participantes lembra que o filho havia manifestado a vontade de ser doador de órgãos.

Mas, naquela hora, lembrar que jeito? Agora, que estou conversando, lembrei-me de um dia em que ele falou sobre doação de órgãos e disse: se tiver alguma coisa minha que dê para aproveitar, que aproveitem! Só que nunca mais lembrei disso. Só lembrei agora. (F5-E1)

A decisão pela não doação de órgãos está circunscrita ao interim de tempo e ao contexto interacional de dor e sofrimento vivido pela família. Diante das incertezas do que poderá acontecer com o familiar, do inesperado da situação, do desconhecimento da ME e da urgência na tomada de decisão, a família vê sua vida desmoronando. Sem tempo para resgatar elementos do convívio familiar e da posição de outros membros da família que contribuam na elaboração de significados, o processo reflexivo é desencadeado por uma vivência de incertezas. Então, o significado atribuído a ME e a doação de órgão relaciona-se a intensificação da perda, fortalecendo a decisão pela não doação.

\section{Limitações do estudo}

Ter como local de investigação um serviço público de referência no diagnóstico de ME e doação de órgãos apresenta-se como uma limitação do estudo, pois contribuiu para o número reduzido de famílias entrevistadas que optaram pela não doação e restringe a possibilidade de generalização dos resultados. Além disso, a necessidade de acessar os prontuários, que apresentavam informações incompletas sobre a localização dos potenciais participantes, limitou a amostra.

\section{CONCLUSÃO}

Os resultados permitem compreender que a experiência vivida pela família ao ter um familiar com ME, resultante de um evento inesperado, interrompe a normalidade do curso de vida, desorganiza seu status quo e a impele a interagir com elementos simbólicos de um contexto desconhecido, de dor, sofrimento e morte, exigindo que, em um curto 
espaço de tempo, acesse informações que a permita tomar decisões acerca da possibilidade de doação de órgãos. As incertezas e a desconfiança de compreender e interpretar os fatos e as informações recebidas, permeia as interações da família com a equipe de saúde e com as ocorrências que se sucedem, deixando-a vulnerável, insegura e fragilizada. Além disso, a perspectiva de que a doação de órgãos pode vir a ser um fator de mais sofrimento, contrariedade e discórdia familiar, contribui para a decisão de não doação.

A vivência das famílias possibilita ampliar o conhecimento sobre a temática da ME e da doação de órgãos, evidenciando que os relacionamentos interpessoais estabelecidos nesse ambiente, quando sensíveis para reconhecer e acolher a dor, o sofrimento e a insegurança, respeitosos das singularidades de cada família, e disponíveis para informar e esclarecer dúvidas, constituem-se em recursos que podem ajudá-la a decifrar os elementos desconhecidos, (re)organizar os pensamentos e decidir quanto a doação ou não.

\section{REFERÊNCIAS}

1. Cajado MCV. The family experience in light of the possibility of organ and tissue donation for transplantation. Revista Psicologia, Diversidade e Saúde. 2017 [cited 2020 May 03]; 6(2):114-20. DOI: http://dx.doi.org/10.17267/23173394rpds.v6i2.1069.

2. Conselho Federal de Medicina (Br). Resolução CFM no 2.173/2017. Define os critérios do diagnóstico de morte encefálica. Diário Oficial da União de15 dezembro de 2017, seção I, p.274-6. [Internet]. [cited 2020 May 03]. Available from: https://sistemas.cfm.org.br/normas/visualizar/resolucoes/BR/2017/2173.

3. Graf CP, Silva OC. Organ donation and transplantation: a binomial to be optimized. Medicina (Ribeirão Preto). 2017 [cited 2020 May 14]; 50(5):345-8. DOI: https://doi.org/10.11606/issn.2176-7262.v50i5p345-348.

4. Ribeiro KRA, Prado LS, Santos FR, Gonçalves FAF, Borges MM, Abreu EP. Brain death and the process of donation of organs: a family care. J. res.: fundam. care. Online. 2020 [cited 2020 May 12]; 12:182-8. DOI: http://dx.doi.org/10.9789/21755361.rpcfo.v12.7197.

5. Associação Brasileira de Transplante de Órgãos (ABTO). Registro Brasileiro de Transplantes: dados numéricos da doação de órgãos e transplantes realizados por estado e instituição no período de Janeiro/Junho - 2019. Ano XXV no 2. [Internet]. 2019 [cited 2020 Mar 22]. Available from: http://www.abto.org.br/abtov03/Upload/file/RBT/2019/rbt2019-1sem-leitura.pdf.

6. Barreto BS, Santana RJB, Nogueira EC, Fernandez BO, Brito FPG. Factors associated with refusal to donate organs in the state of Sergipe, Brazil. Rev. Bras. Pesqui. Saúde [Internet]. 2016 [cited 2020 Apr 14]; 18(3):40-48. Available from: http://www.periodicos.ufes.br/rbps/article/view/15741.

7. Rossato GC, Girardon-Perlini NMO, Begnini D, Beuter M, Camponogara S, Flores CL. Donate or not to donate: the view of the family before the organ donation. Rev. Min. Enferm. 2017 [cited 2020 Apr 16]; 21(e-1056). DOI: https://doi.org/10.5935/14152762.20170066.

8. Weiss J, Shaw D, Schober R, Abati V, Immer FF. Comité National du Don d'Organes Cndo. Attitudes towards organ donation and relation to wish to donate posthumously. Swiss Med. Wkly. 2017 [cited 2020 Apr 14]; 6;147:w14401. DOI: https://doi.org/10.4414/smw.2017.14401.

9. Cheung CY, Pong ML, Au Yeung SF, Chau KF. Factors affecting the deceased organ donation rate in the Chinese community: an audit of hospital medical records in Hong Kong. Hong Kong Med J. 2016 [cited 2020 Mar 16]; 22(6):570-5. DOI: https://doi.org/10.12809/hkmj164930.

10. Aranda RS, Zillmer JGV, Gonçalves KD, Porto AR, Soares ER, Geppert AK. Profile and reasons for denying the donation of organs and tissues for transplants by familiars. Rev. baiana enferm. 2018 [cited 2020 May 12]; 32:e27560. DOI: https://doi.org/10.18471/rbe.v32.27560.

11. Bertasi RAO, Bertasi TGO, Reigada CPH, Ricetto E, Bonfim KO, Santos LA et al. Profile of potential organ donors and factors related to donation and non- donation of organs in an Organ Procurement Service. Rev. Col. Bras. Cir. 2019 [cited 2020 May 12]; 46(3): e2180. DOI: http://dx.doi.org/10.1590/0100-6991e-201922180.

12. Fonseca PIMN, Balistieri AS, Tavares CMM. Production of subjectivity of persons involved in the interview of organs donation: a view from nursing. Rev. Cuba. Enferm. [Internet]. 2016 [cited 2020 Apr 18]; 32(2). Available from: http://www.revenfermeria.sld.cu/index.php/enf/article/view/286/172.

13. Charon JM. Symbolic Interactionism: an introduction, an interpretation, an integration. 10a ed. New Jersey: Prentice-Hall; 2010.

14. Lieblich A, Tuval-Mashiach R, Zilber T. Narrative research: reading, analysis and interpretation. Thousand Oaks; 1998.

15. Bousso RS. The family decision-making process concerning consent for donating their child's organs: a substantive theory. Texto Contexto Enferm. 2008 [cited 2020 Apr 19]; 17(1):45-54. DOI: https://doi.org/10.1590/S0104-07072008000100005.

16. Knihs NS, Leitzke T, Roza BA, Schirmer J, Domingues TAM. Understanding the experience of family facing hospitalization, brain death, and donation interview. Cienc. cuid. saúde. 2015 [cited 2020 Mar 19]; 14(4):1520-7. DOI: https://doi.org/10.4025/cienccuidsaude.v14i4.26060.

17. Groot J, Hoek M, Hoedemaekers C, Hoitsma A, Schilderman H, Smeets W, et al. Request for organ donation without donor registration: a qualitative study of the perspectives of bereaved relatives. BMC Med Ethics [Internet]. 2016 [cited 2020 Mar 20]; 17:38. Available from: https://bmcmedethics.biomedcentral.com/articles/10.1186/s12910-016-0120-6.

18. Hulme W, Allen J, Manara AR, Murphy PG, Gardiner D, Poppitt E. Factors influencing the family consent rate for organ donation in the UK. Anaesthesia. 2016 [cited 2020 Mar 21]; 71(9):1053-63. DOI: https://doi.org/10.1111/anae.13535. 
19. Moraes EL, Neves FF, Santos MJ, Merighi MAB, Massarollo MCKB. Experiences and expectations of nurses in caring for organ donors and their families. Rev. Esc. Enferm. USP. 2015 [cited 2018 Jun 24]; 49(Esp2):129-35. DOI: https://doi.org/10.1590/S0080-623420150000800018.

20. Chieratto CLD, Gonsaga RAT, Cavasini BV, Thevenard G, Filho JAFS, Cagnoni LC, et al. Impact of professional availability with dedication exclusively in the process of organ donation. J. Health Sci. [Internet]. 2017 [cited 2020 Mar 24]; 19(4):256-61. Available from: https://revista.pgsskroton.com/index.php/JHealthSci/article/view/3968/3716.

21. Ríos A, Carrillo J, López-Navas Al, Ayala-García MA, Sánche A, Ramis G, et al . Does knowledge of the concept of brain death affect the attitude toward donation of algerians residing in spain? R. Transplantation Proceedings. 2020 [cited 2020 Oct 15]; 52(2):465-8. DOI: https://doi.org/10.1016/j.transproceed.2019.12.020. 